\title{
Sclerostin is a possible candidate marker of arterial stiffness: Results from a cohort study in Catania
}

\author{
AGOSTINO GAUDIO $^{1}$, VALERIO FIORE ${ }^{1}$, ROSARIO RAPISARDA ${ }^{1}$, MARIA HELGA SIDOTI $^{1}$, \\ ANASTASIA XOURAFA ${ }^{1}$, ANTONINO CATALANO ${ }^{2}$, GIOVANNI TRINGALI $^{3}$, LUCA ZANOLI $^{1}$, \\ SALVATORE SANTO SIGNORELLI ${ }^{1}$ and CARMELO ERIO FIORE ${ }^{1}$ \\ ${ }^{1}$ Department of Clinical and Experimental Medicine, University of Catania, I-95123 Catania; \\ ${ }^{2}$ Department of Clinical and Experimental Medicine, University of Messina, I-98125 Messina; \\ ${ }^{3}$ Medical and Environmental Research Institute (IRMA), I-95024 Acireale, Italy
}

Received December 30, 2016; Accepted February 13, 2017

DOI: $10.3892 / \mathrm{mmr} .2017 .6390$

\begin{abstract}
Osteoporosis and cardiovascular disease are worldwide public health issues. Recent evidence indicates a possible role of the canonical $\mathrm{Wnt} / \beta$-catenin signalling pathway as a common mediator between these two diseases. The aim of the present study was to investigate the relationship between serum concentrations of sclerostin and Dkk1, two extracellular inhibitors of $\mathrm{Wnt} / \beta$-catenin signalling, with carotid intima-media thickness (CIMT) and with arterial stiffness, evaluated by measuring the pulse wave velocity (PWV) in an ambulatory population of adults. To this aim, 67 subjects were recruited in the "Atherosclerosis and osteoporosis: identification of common pathogenetic factors' investigation. Serum sclerostin levels correlated positively with CIMT ( $\mathrm{r}=0.314$, $\mathrm{p}=0.03$ ) and inversely with the augmentation index, a marker of arterial stiffness $(\mathrm{r}=-0.286, \mathrm{p}<0.05)$, whereas Dkk1 did not. Moreover, in a multivariate linear regression model, sclerostin $[\beta-0.1472 ; p=0.0023$; standard error $(\mathrm{SE})=0.04620]$ was an independent predictor of PWV in the study subjects. Our study shows that, following adjustment for confounders, sclerostin is an independent predictor of arterial stiffness in an ambulatory population, whereas Dkk1 is not.
\end{abstract}

\section{Introduction}

Osteoporosis and cardiovascular disease (CVD) are worldwide public health issues, which represent major factors for mortality and morbidity in elderly populations. Although degenerative

Correspondence to: Professor Agostino Gaudio, Department of Clinical and Experimental Medicine, Internal Medicine Unit, University Hospital 'G. Rodolico', University of Catania, Via Santa Sofia 78, I-95123 Catania, Italy

E-mail: agostino.gaudio@gmail.com

Key words: sclerostin, Dkk1, CIMT, augmentation index, pulse wave velocity changes in bone and atherosclerosis (the most common pathological process resulting in CVD) appear to be related with aging in bone and blood vessels, compelling evidence indicates that the association between these two disorders is independent of age (1-6). It is expected that specific signalling pathways, molecular factors, or bone-derived materials may play a role as common mediators of both diseases (7-10). Among several factors implicated in the complex and multifactorial interdependence of vascular physiology and bone metabolism, the canonical Wnt//-catenin signalling pathway has attracted recent interest (11). This signalling pathway plays an important role in various developmental and physiological processes, including bone mass regulation (12) and vascular cell metabolism $(7,13)$. Wnt signalling is regulated by extracellular and intracellular antagonists. Most soluble extracellular inhibitors neutralise Wnt ligands (frizzled-related proteins - sFRP-1-5, or Wnt inhibitory factor 1/2) or interact with the Wnt receptors lipoprotein receptor-related proteins (LRPs) (sclerostin and Dickkopf-1 or Dkk1). Sclerostin is a 190 amino acid glycoprotein secreted mainly by mature osteocytes, although it is also produced by chondrocytes, cementocytes and by the liver, kidney and vascular wall $(14,15)$. Dkk1 is the most widely studied member of the Dickkopf-related protein family. Dkk1 binds to the transmembrane receptor Kremen, which decreases specific LRPs at the cell surface (16).

Both sclerostin and Dkk1 are secreted into the circulation, and consequently, their levels can be determined in serum samples.

Association studies in clinical settings show that sclerostin and Dkk1 concentrations are altered in metabolic bone diseases, in type 1 and 2 diabetes mellitus $(17,18)$ and in patients with chronic kidney disease (19). The association between sclerostin and arterial wall calcification is however unclear, since it has been reported as positive $(7,20,21)$, negative (22) or lacking $(21,22)$. In pre-dialysis chronic kidney disease, Dkk1 was inversely associated with arterial stiffness, whereas sclerostin showed no association at all (23). In postmenopausal women with type 2 diabetes mellitus, sclerostin serum levels have been reported to be positively (20) or inversely (23) associated with a surrogate marker of atherosclerotic disease such as carotid intima-media thickness (CIMT). 
Although all these data indicate that sclerostin and Dkk1 may play a role as components of the bone-vascular axis, their effect on the vascular calcification processes remains unclear.

The aim of the present study was to investigate, in an ambulatory population of adults, the relationship between serum concentrations of sclerostin and Dkk1 with CIMT (an important non-invasive indicator of subclinical atherosclerosis) $(24,25)$, and with arterial stiffness, evaluated by pulse wave velocity (PWV) measurement, a non-invasive measurement that reflects segmental arterial elasticity $(26,27)$.

\section{Materials and methods}

Study subjects. The present study evaluated a subset of subjects $(n=67)$ recruited in the 'Atherosclerosis and osteoporosis: identification of common pathogenetic factors' investigation, who lived in the urban area of Catania (Sicily, Italy). This large study, supported by the Sicilian Regional Department of Health (DDG N. 0130; January 27, 2012), aimed to investigate in a large cohort of Sicilian subjects, the association between various phenotypes of atherosclerosis and alterations of bone metabolism. A cohort of consecutive subjects (male and female) over 50 years, who applied to the Outpatient Clinic for Metabolic Bone Diseases of the Vittorio Emanuele Hospital and to the 'Medical Angiology' Unit of the Garibaldi Hospital in Catania, between April 2012-November 2013, were considered for enrolment in this study. Exclusion criteria were malignant tumours, chronic kidney disease (serum creatinine $>1.4 \mathrm{mg} / \mathrm{dl}$ ), significant chronic hepatic impairment, malabsorption and use of drugs affecting bone metabolism in the last 12 months. Informed written consent was obtained from all subjects before they entered the study.

Measurement of CIMT. Each subject's carotid artery ultrasonographic examination was performed at room temperature $22-25^{\circ} \mathrm{C}$, with subjects in a lying down position, with the head elevated $45-50^{\circ}$ and a side tilt of $30^{\circ}$ to the right and then the same to the left using the LOGIQ C5 Premium apparatus (GE Healthcare, Milwaukee, WI, USA). CIMT was defined as the mean of ten wall measurements of the viewable distance between the lumen-intima and the media-adventitia interface on both the left and right sides. M-mode examinations were performed bilaterally, $1 \mathrm{~cm}$ proximal to the flow divider on the distal wall of the common carotid artery, at sites free of any discrete plaques. Measurements were taken over three cardiac cycles by a single sonographer. If a discrepancy was observed in measurement values between longitudinal and vertical sections, the smaller value was selected to avoid overestimation. Reproducibility was high, with a CV value for the IMT measurement as low as 3.4\% (Pearson's correlation coefficient for intraobserver reproducibility of 0.97). The CIMT was measured in millimetres and was defined according to the Atherosclerosis Risk in Communities (ARIC) study (28). CIMT was defined as pathological if it was $\geq 0.9 \mathrm{~mm}$ and carotid atherosclerosis was diagnosed if the maximum intima-media thickness of the carotid bifurcation (BIF-IMT) was $\geq 1.2 \mathrm{~mm}$.

Pulse wave analysis. The pulse wave analysis (PWA) technique was used to determine the central aortic pressure and the augmentation index (AIx), as previously described (29).
Briefly, all measurements were made from the radial artery at the wrist by applanation tonometry using a Millar tonometer (SPC-301; Millar Instruments, Houston, TX, USA) by a single investigator. Data were collected directly into a desk-top computer and processed with the SphygmoCor ${ }^{\circledR}$ blood pressure analysis system (BPAS-1; PWV Medical, Sydney, Australia), which allows continuous online recording of the radial artery pressure waveform. The same integral system software was used to calculate an average radial artery waveform and to generate the corresponding ascending aortic pressure waveform using a previously validated transfer factor (30). The central aortic waveform was then analysed to calculate the aortic pressure augmentation, the AIx and the central blood pressure. Augmentation was defined as the pressure difference between the first and second systolic peaks of the central aortic pressure waveform. The AIx was obtained by dividing the augmentation by the pulse pressure and expressing it as a percentage (31). The ejection duration and the subendocardial viability ratio, an index of subendocardial perfusion relative to cardiac workload (32), were also determined. The ejection duration was measured as the time from the foot of the pressure wave to the incisura. The subendocardial viability ratio was calculated as the ratio of the area under the central pressure time curve during diastole to that during systole and was expressed as a percentage. The timing of the reflected wave, calculated as the time between the foot of the pressure wave and the inflection point, was analysed to estimate the aortic PWV and hence aortic stiffness $(32,33)$.

Biochemical analyses. Fasting blood samples were taken for the measurement of calcium corrected for serum albumin $(\mathrm{Ca})$, phosphorus $(\mathrm{P})$ and creatinine (automated routine procedures). Serum B-ALP levels were measured by immunoenzymetric assay (Immunodiagnostic Systems, Inc., Fountain Hills, AZ, USA). Intra- and interassay CVs were 6.5 and $6.4 \%$, respectively, with a detection limit of $0.7 \mu \mathrm{g} / \mathrm{l}$. Serum CTX levels were determined by an ELISA assay (Immunodiagnostic Systems, Inc.). Intra- and interassay CVs were 3 and $10.9 \%$, respectively, with a detection limit of $0.02 \mathrm{ng} / \mathrm{ml}$. Sclerostin and Dkk1 were measured by enzyme immunoassay using commercially available ELISA kits (Biomedica Medizinprodukte, Vienna, Austria). Intra- and inter-assay coefficients of variation (CVs) for sclerostin were 5 and $4 \%$, respectively. The detection limit was $2.6 \mathrm{pmol} / \mathrm{l}$. The mean serum concentration in healthy subjects older than 50 years in our laboratory was $43 \pm 10.82 \mathrm{pmol} / 1$. The detection limit for Dkk1 was $0.38 \mathrm{pmol} / 1$. The mean serum concentration in healthy subjects in our laboratory was $9.02 \pm 4.44 \mathrm{pmol} / \mathrm{l}$.

Statistical analysis. Statistical calculations were performed using the GraphPad InStat version 4 for Windows (GraphPad Software, Inc., San Diego, CA, USA). Data for continuous variables were expressed as mean \pm standard deviation (SD). The normal distribution of values for different parameters was verified using the Kolmogorov-Smirnov test. Comparisons between groups were performed using Student's t-test or the Mann-Whitney U test, as appropriate. Pearson's correlation coefficients (normal distribution) or Spearman tests 
Table I. Patient characteristics.

\begin{tabular}{lccccccr}
\hline & $\mathrm{N}$ & Mean age & BMI $\left(\mathrm{kg} / \mathrm{m}^{2}\right)$ & Hypertension $(\%)$ & Diabetes $(\%)$ & Hyperlipidemia $(\%)$ & Smokers $(\%)$ \\
\hline Total & 67 & $67.4 \pm 9.0$ & $27.61 \pm 4.41$ & $54(80.6)$ & $30(44.8)$ & $42(62.7)$ & $11(16.4)$ \\
Male & 20 & $68.1 \pm 8.6$ & $26.51 \pm 3.89$ & $17(85.0)$ & $7(35.0)$ & $13(65.0)$ & $5(25.0)$ \\
Female & 47 & $67.2 \pm 9.3$ & $28.08 \pm 4.57$ & $37(78.7)$ & $23(48.9)$ & $29(61.7)$ & $6(12.7)$ \\
\hline
\end{tabular}

Table II. Biochemical parameters.

\begin{tabular}{lcccccc}
\hline & $\mathrm{N}$ & Creatinine $(\mathrm{mg} / \mathrm{dl})$ & CTX $(\mathrm{ng} / \mathrm{ml})$ & B-ALP $(\mathrm{U} / \mathrm{l})$ & Sclerostin $(\mathrm{pmol} / \mathrm{l})$ & Dkk1 $(\mathrm{pmol} / \mathrm{l})$ \\
\hline Total & 67 & $0.88 \pm 0.13$ & $0.35 \pm 0.21$ & $21.22 \pm 7.47$ & $12.28 \pm 4.78$ & $17.01 \pm 8.37$ \\
Male & 20 & $0.91 \pm 0.21$ & $0.38 \pm 0.26$ & $20.84 \pm 7.55$ & $13.47 \pm 6.25$ & $15.24 \pm 4.79$ \\
Female & 47 & $0.87 \pm 0.18$ & $0.33 \pm 0.19$ & $21.38 \pm 7.52$ & $11.77 \pm 3.98$ & $17.77 \pm 9.44$ \\
\hline
\end{tabular}

Table III. Vascular parameters.

\begin{tabular}{lccccc}
\hline & $\mathrm{N}$ & $\begin{array}{c}\text { Patients with } \\
\text { plaques (\%) }\end{array}$ & CIMT & PWV & Ag. index \\
\hline Total & 67 & $45(67.2)$ & $1.00 \pm 0.19$ & $6.74 \pm 1.85$ & $40 \pm 10$ \\
Male & 20 & $18(90.0)^{\mathrm{a}}$ & $1.09 \pm 0.19^{\mathrm{a}}$ & $6.83 \pm 1.91$ & $41.3 \pm 8.20$ \\
Female & 47 & $27(57.4)$ & $0.96 \pm 0.17$ & $6.70 \pm 1.85$ & $39.0 \pm 11.0$ \\
\hline
\end{tabular}

${ }^{\mathrm{a}} \mathrm{p}<0.05$ (male vs. female). CIMT, carotid intima-media thickness; PWV, pulse wave velocity.

(non-normal distribution) were used for univariate analyses in association studies. Correlation coefficients between CIMT, PWV and metabolic features were calculated by partial correlation analysis. Multivariate linear regression models were used to estimate the determinants of CIMT and PWV. All models were adjusted for age and BMI. Multicollinearity was examined through calculation of the variance inflation factor (VIF), computed by the following formula: $\mathrm{VIF}=1 /\left(1-\mathrm{R}^{2}\right)$; a value of $\mathrm{VIF} \leq 1$ is assumed to exclude multicollinearity for $\mathrm{x}$ variables. In all statistical analyses, $\mathrm{p}<0.05$ was considered to be statistically significant.

\section{Results}

The characteristics of the study subjects are presented in Table I. There were no significant differences between male and female subjects in age, BMI, hypertension, diabetes, hyperlipidaemia or smoking. Hypertensive subjects presented an increased BMI with respect to normotensive subjects ( 28.32 vs. $\left.25.30 \mathrm{~kg} / \mathrm{m}^{2}, \mathrm{p}=0.02\right)$. With regard to laboratory data (Table II), all of the measured parameters were in the normal range. Male subjects presented a significantly higher CIMT than females and proportionally an increased number of carotid plaques $(90.0$ vs. $57.4 \%, \mathrm{p}<0.05)$ (Table III). No gender differences were observed for PWV and AIx. In univariate analysis, serum sclerostin levels correlated positively with CIMT $(r=0.314, p=0.03)$ and inversely with AIx $(r=-0.286$, $\mathrm{p}<0.05$ ), whereas Dkk1 did not. CIMT correlated positively with serum CTX levels $(\mathrm{r}=0.263, \mathrm{p}<0.05)$. Bone turnover markers correlated positively with each other $(r=0.403$, $\mathrm{p}<0.01)$. In the multivariate linear regression model, PWV was set as a dependent variable, while age, BMI, sclerostin, Dkk1, CTX and B-ALP were set as independent variables. We found that only sclerostin $[\beta-0.1472 ; p=0.0023$; standard error $(\mathrm{SE})=0.04620]$ was an independent predictor of PWV in the study subjects. Moreover, setting CIMT as a dependent variable and age, BMI, sclerostin, Dkk1, CTX and B-ALP as independent variables, we found that CTX $(\beta-0.2095$; $\mathrm{p}=0.05$; $\mathrm{SE}=0.1061$ ) was an independent predictor of CIMT. The calculated VIF shows that all $\mathrm{R}^{2}$ are $<0.75$, confirming that the $\mathrm{x}$ variables are independent of each other, excluding multicollinearity problems.

\section{Discussion}

The present study shows for the first time that, following adjustment for confounders, sclerostin is an independent predictor of arterial stiffness in healthy outpatient subjects, whereas Dkk1 is not.

As is well-known, arterial stiffness increases with age (34) and hypertension (35) and is also enhanced in subjects with diabetes mellitus (36) and atherosclerosis (37). Arterial stiffness can be assessed non-invasively by PWV measurement, that is, the velocity of the pulse wave travelling a given distance between two sites in the arterial system. PWV is associated with mortality and cardiovascular lesions $(38,39)$ and is 
a validated approach for the screening of the atherosclerotic risk (40).

Our results raise the possibility of a specific pluripathological effect of sclerostin on the progression of atherosclerosis, distinct from its effect on bone cells.

Although both sclerostin and Dkk1 are well-recognised regulators in bone metabolism, some controversy exists over the possible role of the $\mathrm{Wnt} / \beta$-catenin signalling pathway in the progression of atherosclerosis and in vascular calcification. Sclerostin serum levels are reported to be positively correlated with carotid-femoral PWV in women with postmenopausal osteoporosis (7) and with coronary artery calcification in patients with non-dialysis kidney disease (41). Sclerostin was also positively correlated with carotid-femoral PWV in patients with CKD (42) and in renal transplantation recipients (43). As for Dkk1, non-significant association with PWV was reported in studies by Hampson et al (7), and Hsu et al (43), whereas Register et al (44) reported an inverse association between Dkk1 and coronary artery and aortoiliac arterial calcified plaques in African-Americans with type 2 diabetes. In contrast with these data, we found that serum sclerostin levels were significantly lower in the high arterial stiffness group. No correlations were found between Dkk1 and arterial stiffness parameters. Setting CIMT as a dependent variable, no significant association was seen with either sclerostin or Dkk1. Both sclerostin and Dkk1 may have an impact not only on bone turnover, but also on cardiovascular disease through the role played by the Wnt/ $\beta$-catenin signalling pathway as an inducer of the vascular osteochondrogenesis process (45). Wnt signalling has multiple effects on the initiation and progression of atherosclerosis, which remains the common dysmetabolic pathway in different cardiovascular diseases, affecting different organs with various degree of clinical evidence.

Wnt signalling induces vascular injury by co-regulating inflammation in vessels. Both endothelial cell proliferation and survival, and monocyte adhesion and migration are in fact enhanced by activation of the $\mathrm{Wnt} / \beta$-catenin pathway $(46,47)$. Sclerostin and Dkk1 are negative regulators of the canonical Wnt signalling pathway and therefore the consequence of an increased availability of either factor would be a disruption of the Wnt signalling cascade. This indicates the hypothesis that increased production of sclerostin and Dkk1 may serve as a negative feedback signal, functioning as a protective response against the progression of atherosclerosis.

In the present study, however, PWV was significantly associated with sclerostin serum levels, but not with serum Dkk1 levels. A discrepancy in the behaviour of these two factors which play almost the same role countering the activation of the Wnt pathway in vascular cells has however been reported in some studies $(23,43,48)$, and may be accounted for by the widespread expression of Dkk1 compared with that of sclerostin. This may eventually determine the differences in distribution of these factors in the bloodstream. On the other hand, some evidence shows a negative association between circulating levels of Dkk1 and arterial stiffness (49) in CKD patients. This indicates that different clinical characteristics of the study patients, and in particular the degree of vascular inflammatory response, may selectively influence the response of sclerostin and Dkk1.
We acknowledge our study has some limitations: firstly the cross-sectional nature of the study measurements, which did not allow us to follow the temporal sequence between the concentration of extracellular inhibitors of Wnt signalling and the progression of the vascular outcome measures; secondly, the sample size is small and might reduce statistical power.

In conclusion, sclerostin, a soluble inhibitor of the Wnt/ $\beta$-catenin pathway, seems to be correlated with arterial stiffness in ambulatory population, but longitudinal studies are necessary to better clarify the role of Wnt signalling and its inhibitors in the pathogenesis of atherosclerotic disease.

\section{References}

1. Farhat GN, Strotmeyer ES, Newman AB, Sutton-Tyrrell K, Bauer DC, Harris T, Johnson KC, Taaffe DR and Cauley JA: Volumetric and areal bone mineral density measures are associated with cardiovascular disease in older men and women: The health, aging, and body composition study. Calcif Tissue Int 79: 102-111, 2006.

2. Farhat GN, Newman AB, Sutton-Tyrrell K, Matthews KA, Boudreau R, Schwartz AV, Harris T, Tylavsky F, Visser M and Cauley JA: Health ABC Study: The association of bone mineral density measures with incident cardiovascular disease in older adults. Osteoporos Int 18: 999-1008, 2007.

3. Jørgensen L, Engstad T and Jacobsen BK: Bone mineral density in acute stroke patients: Low bone mineral density may predict first stroke in women. Stroke 32: 47-51, 2001.

4. Schulz E, Arfai K, Liu X, Sayre J and Gilsanz V: Aortic calcification and the risk of osteoporosis and fractures. J Clin Endocrinol Metab 89: 4246-4253, 2004.

5. Hyder JA, Allison MA, Wong N, Papa A, Lang TF, Sirlin C, Gapstur SM, Ouyang P, Carr JJ and Criqui MH: Association of coronary artery and aortic calcium with lumbar bone density: The MESA Abdominal Aortic Calcium Study. Am J Epidemiol 169: 186-194, 2009.

6. Sinnott B, Syed I, Sevrukov A and Barengolts E: Coronary calcification and osteoporosis in men and postmenopausal women are independent processes associated with aging. Calcif Tissue Int 78: 195-202, 2006

7. Hampson G, Edwards S, Conroy S, Blake GM, Fogelman I and Frost ML: The relationship between inhibitors of the Wnt signalling pathway (Dickkopf-1(DKK1) and sclerostin), bone mineral density, vascular calcification and arterial stiffness in post-menopausal women. Bone 56: 42-47, 2013.

8. Ducy P: The role of osteocalcin in the endocrine cross-talk between bone remodelling and energy metabolism. Diabetologia 54: 1291-1297, 2011.

9. Schwetz V, Pieber T and Obermayer-Pietsch B: The endocrine role of the skeleton: Background and clinical evidence. Eur J Endocrinol 166: 959-967, 2012.

10. Kim KM, Lim S, Moon JH, Jin H, Jung KY, Shin CS, Park KS Jang $\mathrm{HC}$ and Choi SH: Lower uncarboxylated osteocalcin and higher sclerostin levels are significantly associated with coronary artery disease. Bone 83: 178-183, 2016.

11. MacDonald BT, Tamai K and He X: Wnt/ $\beta$-catenin signaling: Components, mechanisms, and diseases. Dev Cell 17: 9-26, 2009.

12. Krishnan V, Bryant HU and Macdougald OA: Regulation of bone mass by Wnt signaling. J Clin Invest 116: 1202-1209, 2006.

13. Reis M and Liebner S: Wnt signaling in the vasculature. Exp Cell Res 319: 1317-1323, 2013.

14. Moester MJ, Papapoulos SE, Löwik CW and van Bezooijen RL: Sclerostin: Current knowledge and future perspectives. Calcif Tissue Int 87: 99-107, 2010.

15. Brabnikova-Maresova K, Jarosova K, Pavelka K and Stepan JJ: Serum sclerostin in high-activity adult patients with juvenile idiopathic arthritis. Arthritis Res Ther 16: 460, 2014.

16. Mao B, Wu W, Davidson G, Marhold J, Li M, Mechler BM, Delius H, Hoppe D, Stannek P, Walter C, et al: Kremen proteins are Dickkopf receptors that regulate Wnt/ $\beta$-catenin signalling. Nature 417: 664-667, 2002.

17. Gennari L, Merlotti D, Valenti R, Ceccarelli E, Ruvio M, Pietrini MG, Capodarca C, Franci MB, Campagna MS, Calabrò $\mathrm{A}$, et al: Circulating sclerostin levels and bone turnover in type 1 and type 2 diabetes. J Clin Endocrinol Metab 97: 1737-1744, 2012. 
18. Gaudio A, Privitera F, Battaglia K, Torrisi V, Sidoti MH, Pulvirenti I, Canzonieri E, Tringali G and Fiore CE: Sclerostin levels associated with inhibition of the Wnt/ $\beta$-catenin signaling and reduced bone turnover in type 2 diabetes mellitus. J Clin Endocrinol Metab 97: 3744-3750, 2012

19. Cejka D, Herberth J, Branscum AJ, Fardo DW, MonierFaugere MC, Diarra D, Haas M and Malluche HH: Sclerostin and Dickkopf-1 in renal osteodystrophy. Clin J Am Soc Nephrol 6: 877-882, 2011.

20. Morales-Santana S, García-Fontana B, García-Martín A, Rozas-Moreno P, García-Salcedo JA, Reyes-García R and Muñoz-Torres M: Atherosclerotic disease in type 2 diabetes is associated with an increase in sclerostin levels. Diabetes Care 36: 1667-1674, 2013

21. Kuipers AL, Miljkovic I, Carr JJ, Terry JG, Nestlerode CS, Ge Y, Bunker CH, Patrick AL and Zmuda JM: Association of circulating sclerostin with vascular calcification in Afro-Caribbean men. Atherosclerosis 239: 218-223, 2015

22. Claes KJ, Viaene L, Heye S, Meijers B, d'Haese P and Evenepoel P: Sclerostin: Another vascular calcification inhibitor? J Clin Endocrinol Metab 98: 3221-3228, 2013.

23. Gaudio A, Privitera F, Pulvirenti I, Canzonieri E, Rapisarda R and Fiore CE: The relationship between inhibitors of the Wnt signalling pathway (sclerostin and Dickkopf-1) and carotid intima-media thickness in postmenopausal women with type 2 diabetes mellitus. Diab Vasc Dis Res 11: 48-52, 2014.

24. Bauer M, Caviezel S, Teynor A, Erbel R, Mahabadi AA and Schmidt-Trucksäss A: Carotid intima-media thickness as a biomarker of subclinical atherosclerosis. Swiss Med Wkly 142 w13705, 2012.

25. van den Oord SC, Sijbrands EJ, ten Kate GL, van Klaveren D, van Domburg RT, van der Steen AF and Schinkel AF: Carotid intima-media thickness for cardiovascular risk assessment: Systematic review and meta-analysis. Atherosclerosis 228: 1-11, 2013.

26. Tomiyama $\mathrm{H}$ and Yamashina A: Non-invasive vascular function tests: Their pathophysiological background and clinical application. Circ J 74: 24-33, 2010.

27. Mitchell GF, Hwang SJ, Vasan RS, Larson MG, Pencina MJ Hamburg NM, Vita JA, Levy D and Benjamin EJ: Arterial stiffness and cardiovascular events: The Framingham Heart Study. Circulation 121: 505-511, 2010.

28. Nambi V, Chambless L, Folsom AR, He M, Hu Y, Mosley T, Volcik K, Boerwinkle E and Ballantyne CM: Carotid intima-media thickness and presence or absence of plaque improves prediction of coronary heart disease risk: The ARIC (Atherosclerosis Risk In Communities) study. J Am Coll Cardiol 55: 1600-1607, 2010.

29. Alagona C, Soro A, Westerbacka J, Ylitalo K, Salonen JT, Salonen R, Yki-Järvinen $\mathrm{H}$ and Taskinen MR: Low HDL cholesterol concentration is associated with increased intima-media thickness independent of arterial stiffness in healthy subjects from families with low HDL cholesterol. Eur J Clin Invest 33: 457-463, 2003.

30. Pauca AL, O'Rourke MF and Kon ND: Prospective evaluation of a method for estimating ascending aortic pressure from the radial artery pressure waveform. Hypertension 38: 932-937, 2001.

31. Kelly R, Hayward C, Avolio A and O'Rourke M: Noninvasive determination of age-related changes in the human arterial pulse. Circulation 80: 1652-1659, 1989.

32. Wilkinson IB, MacCallum H, Rooijmans DF, Murray GD, Cockcroft JR, McKnight JA and Webb DJ: Increased augmentation index and systolic stress in type 1 diabetes mellitus. QJM 93: 441-448, 2000.

33. Wilkinson IB, Prasad K, Hall IR, Thomas A, MacCallum H, Webb DJ, Frenneaux MP and Cockcroft JR: Increased central pulse pressure and augmentation index in subjects with hypercholesterolemia. J Am Coll Cardiol 39: 1005-1011, 2002.
34. Avolio AP, Chen SG, Wang RP, Zhang CL, Li MF and O'Rourke MF: Effects of aging on changing arterial compliance and left ventricular load in a northern Chinese urban community. Circulation 68: 50-58, 1983

35. Nichols WW and O'Rourke MF: Properties of the arterial wall. In: McDonald's Blood Flow in Arteries: Theoretical, Experimental and Clinical Principles. 3rd edition. Edward Arnold, London, pp77-114, 1990.

36. Lehmann ED, Gosling RG and Sönksen PH: Arterial wall compliance in diabetes. Diabet Med 9: 114-119, 1992.

37. Wada T, Kodaira K, Fujishiro K, Maie K, Tsukiyama E, Fukumoto T, Uchida T and Yamazaki S: Correlation of ultrasound-measured common carotid artery stiffness with pathological findings. Arterioscler Thromb 14: 479-482, 1994.

38. Amar J, Ruidavets JB, Chamontin B, Drouet L and Ferrières J: Arterial stiffness and cardiovascular risk factors in a population-based study. J Hypertens 19: 381-387, 2001.

39. Blacher J, Asmar R, Djane S, London GM and Safar ME: Aortic pulse wave velocity as a marker of cardiovascular risk in hypertensive patients. Hypertension 33: 1111-1117, 1999

40. Cruickshank K, Riste L, Anderson SG, Wright JS, Dunn G and Gosling RG: Aortic pulse-wave velocity and its relationship to mortality in diabetes and glucose intolerance: An integrated index of vascular function? Circulation 106: 2085-2090, 2002.

41. Morena M, Jaussent I, Dupuy AM, Bargnoux AS, Kuster N, Chenine L, Leray-Moragues H, Klouche K, Vernhet H, Canaud B, et al: Osteoprotegerin and sclerostin in chronic kidney disease prior to dialysis: Potential partners in vascular calcifications. Nephrol Dial Transplant 30: 1345-1356, 2015.

42. Desjardins L, Liabeuf S, Oliveira RB, Louvet L, Kamel S, Lemke HD, Vanholder R, Choukroun G and Massy ZA; European Uremic Toxin (EUTox) Work Group: Uremic toxicity and sclerostin in chronic kidney disease patients. Nephrol Ther 10: 463-470, 2014.

43. Hsu BG, Liou HH, Lee CJ, Chen YC, Ho GJ and Lee MC: Serum sclerostin as an independent marker of peripheral arterial stiffness in renal transplantation recipients: A cross-sectional study. Medicine (Baltimore) 95: e3300, 2016.

44. Register TC, Hruska KA, Divers J, Bowden DW, Palmer ND, Carr JJ, Wagenknecht LE, Hightower RC, Xu J, Smith SC, et al: Plasma Dickkopf1 (DKK1) concentrations negatively associate with atherosclerotic calcified plaque in African-Americans with type 2 diabetes. J Clin Endocrinol Metab 98: E60-E65, 2013.

45. Evrard S, Delanaye P, Kamel S, Cristol JP, Cavalier E, Arnaud J, Zaoui P, Carlier MC, Laville M, Fouque D, et al: SFBC/SN joined working group on vascular calcifications: Vascular calcification: From pathophysiology to biomarkers. Clin Chim Acta 438: 401-414, 2015.

46. Arderiu G, Espinosa S, Peña E, Aledo R and Badimon L: Monocyte-secreted Wnt5a interacts with FZD5 in microvascular endothelial cells and induces angiogenesis through tissue factor signaling. J Mol Cell Biol 6: 380-393, 2014.

47. Lee DK, Nathan Grantham R, Trachte AL, Mannion JD and Wilson CL: Activation of the canonical Wnt/ $\beta$-catenin pathway enhances monocyte adhesion to endothelial cells. Biochem Biophys Res Commun 347: 109-116, 2006.

48. Lim Y, Kim CH, Lee SY, Kim H, Ahn SH, Lee SH, Koh JM, Rhee Y, Baek KH, Min YK, et al: Decreased plasma levels of sclerostin but not Dickkopf-1 are associated with an increased prevalence of osteoporotic fracture and lower bone mineral density in postmenopausal Korean women. Calcif Tissue Int 99: 350-359, 2016.

49. Thambiah S, Roplekar R, Manghat P, Fogelman I, Fraser WD, Goldsmith D and Hampson G: Circulating sclerostin and Dickkopf-1 (DKK1) in predialysis chronic kidney disease (CKD): Relationship with bone density and arterial stiffness. Calcif Tissue Int 90: 473-480, 2012. 